\title{
AINDA AIDA? - UMA REVISÃO HISTÓRICO-CRÍTICA DA HIERARQUIA DOS EFEITOS PUBLICITÁRIOS
}

\author{
AIDA yet? - A historical and critical review of hierarchy of advertising effects
}
Todavía AIDA? - Una revisión histórico-crítica de la jerarquía de los efectos de la publicidad

Rodolfo Rorato Londero

Professor na Universidade Estadual de Londrina

rodolfolondero@hotmail.com

\begin{abstract}
Resumo
O objetivo deste artigo é realizar uma revisão histórico-crítica do modelo AIDA (AtençãoInteresse-Desejo-Ação), bastante conhecido por explicar os efeitos da publicidade. Pretendese também revisar outras hierarquias dos efeitos publicitários, consideradas desenvolvimentos ou modificações radicais do modelo AIDA. Procura-se entender porque esse modelo perdura por mais de um século, constatando que isto se deve não por causa da confirmação de dados empíricos, mas porque o modelo se ajusta à visão cultural e organizacional dominante. Por fim, apresenta-se as principais críticas à hierarquia dos efeitos, problematizando desde a noção básica de processo sequencial até a subordinação dos elementos emotivos.
\end{abstract}

Palavras-chave: Modelo AIDA; Hierarquia dos efeitos publicitários; Fenomenologia.

\begin{abstract}
The aim of this paper is to conduct a historical and critical review of AIDA model (AttentionInterest-Desire-Action), well known for explaining the effects of advertising. We also intended to review other hierarchies of advertising effects, considered developments or radical changes of AIDA model. This paper try to understand why this model persists for more than a century, noting that it is not because the confirmation of empirical data, but because the model fits the dominant cultural and organizational worldview. Finally, we present the main criticisms of the hierarchy of effects, from the basic notion of sequential process to the subordination of the emotive elements.
\end{abstract}

Key words: AIDA model; Hierarchy of advertising effects; Phenomenology.

\section{Resumen}

El propósito de este trabajo es realizar una revisión histórico-crítica del modelo AIDA (Atención-Interés-Deseo-Acción), bien conocido para explicar los efectos de la publicidad. Se pretende revisar también otras jerarquías de efectos de la publicidad, consideradas desarrollos o cambios radicales en el modelo AIDA. Queremos entender por qué este modelo persiste durante más de un siglo, sabiendo de que esto no es debido a la confirmación de los datos 
empíricos, sino porque el modelo se ajusta a la visión cultural y organizacional dominante. Por último, se presentan las principales críticas a la jerarquía de efectos, como la noción básica de proceso secuencial y la subordinación de los elementos emotivos.

Palabras clave: Modelo AIDA; Jerarquía de efectos de la publicidad; Fenomenología.

\section{INTRODUÇÃO}

Como é possível um modelo de publicidade perdurar por mais de um século justamente em uma área conhecida pela criatividade? Este é o caso do modelo AIDA (Atenção-Interesse-Desejo-Ação), desenvolvido originalmente no final do século XIX. Segundo este modelo, a publicidade deve sucessivamente atrair a atenção do consumidor, suscitar seu interesse por informações do produto, despertar seu desejo e, finalmente, provocar a ação de compra. Amplamente endossado nos manuais brasileiros de publicidade ${ }^{1}$ (MALANGA, 1987, p. 48; SAMPAIO, 1999, p. 38; SANT’ANNA, 2001, p. 78), o modelo AIDA é, na verdade, apenas a forma mais conhecida de hierarquia dos efeitos, definição referente aos diversos modelos de publicidade que compreendem os efeitos como um processo sequencial envolvendo cognição, afeição e conação.

Em seu levantamento histórico das hierarquias, Barry (1987) reconhece mais de 40 variações do modelo AIDA, acrescentando efeitos como satisfação, percepção, memória, etc., além de versões completamente modificadas do modelo original. Este número continua crescendo, como podemos perceber na proposta recente de Wijaya (2012), cujo modelo AISDALSLove (Atenção-Interesse-Pesquisa-Desejo-Ação-Gostar/DetestarCompartilhar-Amar/Odiar) busca considerar efeitos a curto e longo prazo, além de enfatizar o momento pós-compra e o consumidor crítico conectado às redes sociais online.

Buscando compreender a ênfase concedida à hierarquia dos efeitos, bem como realizar sua crítica necessária, o objetivo deste artigo é revisar o percurso histórico desse conceito, destacando desde as primeiras formulações até suas mais conhecidas mudanças. Para tanto, seguiremos a periodização proposta por Barry (1987), dividida em três fases: $\left(1^{\text {a }}\right)$ fase do desenvolvimento inicial, do final do século XIX até o final da década de 1950; (2a) fase do desenvolvimento moderno, do início da década de 1960 até os dias de hoje; e ( $3^{\text {a }}$ ) fase da

\footnotetext{
${ }^{1}$ Exceção ao manual Tudo que você queria saber sobre a propaganda e ninguém teve paciência para explicar, onde o capítulo "Eficiência publicitária e pesquisa de comunicação", de Vera Aldrighi, apresenta críticas às hierarquias dos efeitos, considerando-as "modelos teóricos com pretensões ambiciosas e universalistas" (ALDRIGHI, 1995, p. 60).
} 
objeção, ocorrida contemporaneamente à fase anterior. Depois apresentaremos as principais críticas à hierarquia dos efeitos, problematizando desde a noção básica de processo sequencial até a subordinação dos elementos emotivos.

\section{FASE DO DESENVOLVIMENTO INICIAL}

Um dado determinante do percurso histórico do modelo AIDA encontra-se já em sua primeira menção, pois ela não surgiu no campo da publicidade, mas sim no das vendas. Em 1898 St. Elmo Lewis afirmou que o sucesso das vendas envolve atrair a atenção, manter o interesse e criar o desejo nos compradores; por volta de 1900 ele acrescentou o quarto elemento que consagraria o modelo, levar à ação (BARRY, 1987, p. 252). Escrevendo mais tarde sobre publicidade para bancos e seguradoras, Lewis apresentou as quatro etapas resumidas em "três fundamentos": "Você deve atraí-los para sua proposta. Você deve mantêlos interessados. Você deve convencê-los da necessidade de agir"2 (LEWIS, 1908, p. 77). Percebe-se implicitamente a noção de processo sequencial quando Lewis comenta a respeito do "maior problema na mente do anunciante": "Se nós não pudermos ganhar a atenção do leitor, é manifestamente impossível para nós interessá-lo e convencê-lo" (LEWIS, 1908, p. 95).

Também no campo das vendas, em The Art of Selling (1911), Arthur Sheldon acrescenta ao modelo de Lewis um quinto elemento ("satisfação permanente"), além de adjetivar o primeiro (“atenção favorável”) e tornar explícita a noção de processo sequencial: "a segunda etapa depende da primeira; a terceira da segunda; e assim até o fim" (SHELDON, 1911, p. 28). Através desse quinto elemento, Sheldon mostra-se como o primeiro e um dos poucos teóricos da hierarquia dos efeitos a considerar o momento pós-compra (WIJAYA, 2012, p. 79). Sheldon também é um dos poucos a discutir os elementos opostos associados ao modelo: (1) atenção desfavorável; (2) indiferença; (3) desgosto; (4) repulsão; e (5) nenhuma venda (SHELDON, 1911, p. 30).

Ou seja, mesmo atraindo a atenção favorável, o vendedor/anúncio pode causar indiferença no comprador, interrompendo o processo. Outra característica notável em The Art of Selling é a antecipação da famosa divisão tripartida da hierarquia dos efeitos, porém Sheldon apresenta outros termos, ao invés dos conhecidos cognição, afeição e conação (ver próximo tópico): "Em cada mente existem três poderes, classificados como conhecimento,

\footnotetext{
${ }^{2}$ Esta e as demais citações em língua estrangeira são livremente traduzidas por nós.
} 
sentimento e vontade. Atenção tem a ver com o poder do conhecimento; interesse e desejo têm a ver com o poder do sentimento; e ação tem a ver com o poder da vontade (SHELDON, 1911, p. 31; grifos do autor).

Denominada de "Venda e publicidade", a lição 49 de The Art of Selling nos traz de volta ao dado determinante referido no início deste tópico. Para Sheldon, tanto o sucesso das vendas individuais quanto o dos anúncios são garantidos pelos mesmos princípios: "um redator de anúncio tenta apelar para o desejo humano e estimular uma decisão; e ele faz isto prendendo a atenção e criando o interesse” (SHELDON, 1911, p. 177). Na verdade, como afirma o autor, "tem sido dito que 'a publicidade é a venda impressa', uma definição que, embora não seja totalmente verdadeira, é suficientemente verdadeira para indicar o fato que a publicidade é um ramo das vendas" (SHELDON, 1911, p. 177).

Proferida pela primeira vez em 1905 por John E. Kennedy, “a publicidade é a venda impressa" levou Albert Lasker a fundar a publicidade moderna, definindo as "notícias do mercado" como anúncios e identificando os redatores como publicitários (EGUIZÁBAL, 2010, p. 41-43). Contudo, apesar da importância dessa frase para a história da publicidade, Heath e Feldwick a criticam: "A analogia das vendas encara a tarefa da publicidade como a conversão de uma perspectiva de não-compra em compra. Mas essa imagem é bastante inapropriada nas situações de compra repetida, sobre as quais muito da publicidade diz respeito" (HEATH; FELDWICK, 2008, p. 35).

Ou seja, um anúncio não precisa chamar a atenção e nem despertar o interesse de um comprador frequente. Jones também concorda com essa crítica, acrescentando que, "em particular, os usuários de uma marca normalmente são aqueles mais conscientes da publicidade que envolve a marca" (JONES, 2002, p. 235). Neste caso, contrariando a sequência canônica do modelo, a compra repetida provoca consciência da publicidade (ver próximo tópico). Por essas razões, Jones cita a publicidade de resposta direta como a mais adequada para se empregar o modelo AIDA, pois, como as vendas individuais, ela também visa funcionar como "um estímulo completo" (JONES, 2002, p. 236).

Afastando-se gradativamente dos manuais de vendas, a publicidade buscou sua legitimidade no campo da psicologia, sendo a primeira disciplina a abordá-la seriamente (EGUIZÁBAL, 2010, p. 14). No início do século XX, pesquisadores como Herbert Hess (1910), Harry Hollingworth (1913), Daniel Starch (1914), Harry Tipper e George Hotchkiss (1914), entre outros, defendiam a pesquisa em publicidade como domínio exclusivo da psicologia. Em The psychology of advertising (1908), por exemplo, Walter D. Scott afirma 
que, "como a publicidade lida com a menta humana, sua única base científica é a psicologia, que é o estudo sistemático daquelas mesmas mentes que o anunciante busca influenciar" (SCOTT, 1913, p. 2). Entretanto, o modelo originário das vendas acompanhou a publicidade nessa transição para a psicologia. Por exemplo, Starch propõe três das quatro etapas do modelo AIDA: "atrair a atenção, estimular o interesse e garantir uma resposta" (STARCH, 1914, p. 24; grifos do autor). Por sua vez, Hollingworth descreve um processo detalhado, porém semelhante aos demais:

1. O estímulo captura a atenção, vem à tona, se separa das outras impressões. 2. A impressão ou (a) sai imediatamente da consciência ou (b) retém a atenção, i. e., torna-se dominante na consciência e causa ajustamentos do órgão perceptivo para um exame atento.

3. Ao fazer isto, ela desperta associações, memórias, interesses, sentimentos e torna-se firmemente anexada a tudo isto; a impressão é fixada e permanece como ideia ou imagem.

4. Isto leva a uma resposta motora. Esta resposta é um fator essencial para determinar o sentido final do apelo. Tanto psicologicamente quanto comercialmente, a resposta é um dos elementos mais importante de todo o processo (HOLLINGWORTH, 1913, p. 28-29).

Por sua vez, Tipper e Hotchkiss (1914, p. 41) apresentam o modelo AIDA quase integralmente, substituindo a última etapa por "convicção", como fez Lewis em seus três fundamentos. Os autores também adiantam a hipótese de publicidade e pessoal de vendas trabalharem as etapas em conjunto: "Nem todos os anúncios colocam ênfase igual nesses quatro elementos, alguns visam mais atrair a atenção e o interesse, deixando ao vendedor criar o desejo e assegurar a convicção para fechar a venda" (TIPPER; HOTCHKISS, 1914, p. 41 42).

Deste modo, a publicidade não é inteiramente responsável pela realização da compra, pois ela atua em conjunto com outras forças de marketing (ver próximo tópico). Podemos dizer que essa conclusão é o principal avanço dos pioneiros da hierarquia dos efeitos: para eles, "a eficácia da publicidade deveria ser medida por seu impacto em uma hierarquia de respostas comunicacionais, como a habilidade da audiência reconhecer marcas, lembrar dos principais pontos, gerar atitudes positivas, alterar uma imagem, e assim por diante" (BARRY, 1987, p. 277). Por exemplo, se a publicidade fixa determinada marca na memória do consumidor, então ela facilita a compra no ponto de venda. Essa conclusão demarca o desenvolvimento moderno da hierarquia dos efeitos. 


\section{FASE DO DESENVOLVIMENTO MODERNO}

É somente a partir dos anos 1960 que os princípios da hierarquia dos efeitos tornam-se claros, inviabilizando as vendas imediatas como único critério de mensuração da eficácia publicitária. Nos primeiros parágrafos de "A model for predictive measurements of advertising effectiveness" (1961), Robert Lavidge e Gary Steiner questionam

quais são as funções da publicidade? Obviamente sua função final é ajudar produzir vendas. Mas toda publicidade não é, não deve e não pode ser desenhada para produzir compras imediatas por todos aqueles expostos a ela. Resultados de vendas imediatas (mesmo se mensuráveis) são, no melhor, um critério incompleto de eficácia publicitária.

(...) Consumidores definitivos normalmente não se transformam de indivíduos desinteressados em compradores convencidos em uma única etapa instantânea. Ao contrário, eles alcançam a compra almejada através de um processo ou série de etapas no qual a compra realizada é apenas o limite final (LAVIDGE; STEINER, 1961, p. 59; grifo dos autores).

Segundo Barry e Howard (1999, p. 99), entre os modelos de hierarquia dos efeitos, as sete etapas propostas por Lavidge e Steiner são as mais citadas: (1) desconhecimento; (2) consciência; (3) conhecimento; (4) afeição; (5) preferência; (6) convicção; (7) compra. Os autores também reconhecem, pela primeira vez, como o consumo de produtos diferentes desenvolve a hierarquia de formas diferentes: "Uma compra impulsiva pode ser consumada sem nenhuma consciência, conhecimento, preferência ou convicção prévia. Por outro lado, um bem industrial ou um produto de consumo importante frequentemente não será comprado dessa maneira” (LAVIDGE; STEINER, 1961, p. 60). Como veremos no próximo tópico, a conhecida "grade FCB" toma essa permissa como um de seus pontos de partida.

Entretanto, a principal contribuição do artigo de Lavidge e Steiner é relacionar as etapas da hierarquia dos efeitos às três dimensões do modelo psicológico clássico: a dimensão cognitiva (estados intelectual, mental ou "racional"), a dimensão afetiva (estados "emocional" ou "sentimental") e a dimensão conativa (estado comportamental) (LAVIDGE; STEINER, 1961, p. 60). Considerando o modelo AIDA, por exemplo, a atenção e o interesse dizem respeito à dimensão cognitiva, o desejo à afetiva e a ação à conativa. Isto permite aos pesquisadores adotarem conceitos comuns, ainda que nem sempre eles estejam de acordo quanto à precedência de cada um, como veremos adiante.

Igualmente famoso, o modelo DAGMAR (Defining advertisings goals for measured advertising results), proposto por Russel H. Colley em 1961, também adota a hierarquia dos 
efeitos, reconhecendo de antemão que sua "fórmula talvez seja tão velha quanto a publicidade, as vendas ou qualquer outra forma de comunicação persuasiva" (COLLEY, 1976, p. 48). Nas palavras de Colley, “toda comunicação comercial que visa, em última instância, à compra de um produto, deverá ter quatro níveis de entendimento", partindo do desconhecimento do consumidor para (1) a consciência: "O consumidor tem que ter, inicialmente, consciência de uma marca ou fabricante; (2) a compreensão: "Ele precisa ter uma compreensão do que é o produto e o que pode ser oferecido a ele”; (3) a convicção: "O consumidor deverá chegar a uma pré-disposição, ou convicção mental, de compra; e (4) a ação: "Finalmente ele é levado à ação de compra, por auto-impulso" (COLLEY, 1976, p. 48).

Como em qualquer hierarquia dos efeitos, esses níveis são atingidos sucessivamente e, muitas vezes, através de vários estímulos publicitários: "Raramente uma simples publicidade tem força suficiente para mudar as coisas de um estado de desconhecimento para a condição de ação. (...) Os resultados de uma publicidade devem ser medidos dinamicamente, ou seja, em que extensão as pessoas são levadas de um nível a outro" (COLLEY, 1976, p. 50). Por causa da publicidade atuar em níveis diferentes e em momentos diferentes, Colley acredita que "não podemos medir a força da publicidade somente em termos da ação de compra do produto" (COLLEY, 1976, p. 46), criticando assim as pesquisas que tomam este critério como exclusivo.

Colley também reconhece que "a publicidade é [apenas] uma das várias forças que contribuem para a tomada de consciência, compreensão, convicção e ação", sendo necessária a soma de outras forças de marketing (promoção, vendedores, disponibilidade, preço, embalagem, etc.) para que um consumidor atinja o último nível de entendimento, ou seja, realize a compra (COLLEY, 1976, p. 67). Por outro lado, existem forças de oposição, como é o caso da competição, da resistência às vendas, do desgaste do mercado e dos lapsos de memória do consumidor (COLLEY, 1976, p. 69).

Também é nesta fase que o termo "hierarquia dos efeitos" é mencionado pela primeira vez. Em "The hypothesis of a hierarchy of effects: a partial evaluation" (1966), Kristian Palda avalia a hipótese da hierarquia dos efeitos a partir das dimensões psicológicas relacionadas por Lavidge e Steiner. A respeito da dimensão conativa, Palda é muito breve, mencionando apenas a dificuldade em relacionar os efeitos da publicidade sobre o comportamento de compra sem criar pseudocausalidades (PALDA, 1966, p. 17).

A respeito da dimensão cognitiva, Palda mostra como a capacidade de mensurar reconhecimento e lembrança possibilitou o avanço das pesquisas nesta área; entretanto, até 
aquele momento (e até hoje), a questão fundamental não havia sido respondida: é a lembrança do anúncio que aumenta os resultados de compra ou é o contrário? (PALDA, 1966, p. 16). A dimensão cognitiva seria de fato a primeira etapa da hierarquia dos efeitos? Como vimos anteriormente, este não é o caso das compras repetidas, quando os consumidores já conhecem o produto que os interessa.

Por fim, a respeito da dimensão afetiva, o problema é justamente o contrário, pois qual critério utilizar para mensurá-la? (PALDA, 1966, p. 150). Para Barry (1987, p. 274-275), as pesquisas sobre o papel da dimensão afetiva no comportamento do consumidor mostram como essa dimensão é difícil de definir e de operacionalizar, contribuindo para sua posição subordinada em relação à dimensão cognitiva nas hierarquias dos efeitos. Para Heath e Feldwick (2008, p. 42), a dificuldade em quantificar elementos não-cognitivos levou os pesquisadores e as agências de publicidade a adotarem o que os autores chamam de modelo de processamento informacional (modelo IP).

Para este modelo, os anúncios são pensados como mensagens informacionais e racionais, ainda que revestidos de emoções. Como demonstram Heath e Feldwick (2008), o sucesso duradouro de duas "fórmulas" mostra a aceitação do modelo IP: o já mencionado esquema AIDA, cuja precedência da dimensão cognitiva reforça a permissa do modelo, e a proposta de venda única (Reevers), pois limita o anúncio a um argumento verbal e racional. A adoção do modelo IP também se justifica devido ao medo social em torno da suposta manipulação publicitária:

\begin{abstract}
Enquanto a publicidade se apresenta como oferecendo essencialmente informação factual a consumidores que tomam decisões conscientes $\mathrm{e}$ racionais, ela é vista no papel de "advogada honesta" e lhe será permitida uma quantidade considerável de liberdade. Contudo, se a publicidade é vista operando sobre as emoções ou sobre consumidores não-conscientes e nãoracionais, ela pode ser criticada como manipuladora ou como lavagem cerebral (HEATH; FELDWICK, 2008, p. 48).
\end{abstract}

Famoso nos anos 1950, Vance Packard é o principal responsável por essa relação entre publicidade e lavagem cerebral, celebrada em Hidden Persuaders (1957). Não por acaso, o autor critica as "pesquisas motivacionais", interessadas quase sempre pelos aspectos emocionais e simbólicos da comunicação não-verbal, como um retrocesso à "longa luta [do homem] para tornar-se um ser racional e orientado por si próprio" (PACKARD, 1972, p. 4). A devoção ao consumidor racional, herdeiro do Iluminismo, justifica a ênfase à 
dimensão cognitiva em detrimento da afetiva. Contudo, o impasse em torno da importância da dimensão afetiva possibilitou as primeiras objeções ao conceito de hierarquia dos efeitos, como também a formulação de novas hierarquias.

\section{FASE DA OBJEÇÃO}

Segundo Jones, existem ao menos dois modelos extremos de efeitos da publicidade: “(a) como um processo sequencial lógico (a hierarquia do aprendizado); e (b) como um processo que abarca fluidez e feedback (a hierarquia do envolvimento insuficiente)" (JONES, 2002, p. 234; grifos do autor). Enquanto o primeiro refere-se ao modelo AIDA em outra denominação pela qual também é conhecido, o segundo apresenta um modelo oposto. $\mathrm{Na}$ verdade, na mesma década em que surge o modelo canonizado de Lavidge e Steiner, Herbert Krugman propôs uma hierarquia alternativa para compreender os comerciais de televisão.

Para ele, "muito do impacto da publicidade de televisão é aprendizado sem envolvimento" (KRUGMAN, 2002, p. 183). Ao considerar que "muito do conteúdo da publicidade é assimilado como material sem nenhum sentido", Krugman compreendeu que o mais importante é a ordem de apresentação: “os primeiros e os últimos itens eram os mais lembrados, o que também deu origem aos princípios da primazia e da recentidade" (KRUGMAN, 2002, p. 182-183). Isto justifica a repetição constante dos comerciais de televisão, evitando que sejam esquecidos pelos telespectadores. Contudo, as implicações deste procedimento atingem diretamente o principal artifício atribuído à publicidade: a persuasão. Nas palavras de Krugman,

isso sugere que, se a televisão nos bombardear com um conjunto suficiente de trivialidades sobre um produto, possivelmente seremos persuadidos a acreditar nelas? Pelo contrário, sugere que persuasão desse tipo - isto é, que vence uma atitude de resistência - não tem nenhum envolvimento e que é um erro procurar por ela em nossas vidas pessoais para testar o impacto da publicidade de televisão. Em vez disso, à medida que a trivialidade é repetidamente assimilada e repetidamente esquecida e então repetidamente assimilada um pouco mais, é provável que aconteçam duas coisas: (a) a mais simples, chamada de superaprendizado, deslocará um pouco de informação do sistema de memória de curto prazo para o sistema de longo prazo; (b) de modo mais complexo, permitiremos alterações significativas na estrutura da nossa percepção de uma marca ou produto, mas de maneira que pode ficar aquém da persuasão ou da mudança de atitude. Um possível modo de fazer isso é deslocando a relativa relevância dos atributos que a publicidade nos sugere, à medida que organizamos nossas percepções de marcas e produtos (KRUGMAN, 2002, p. 182). 
Apesar de não resultar em uma atitude de compra imediata, é justamente este segundo efeito, mais complexo, que torna a publicidade televisiva eficaz, pois ele altera a relevância psicológica das estruturas de referência dos telespectadores (KRUGMAN, 2002, p. 182). Acontece que, ao contrário do modelo AIDA, o telespectador não se torna primeiramente consciente do produto para depois comprá-lo: “A situação de compra é a catalisadora que rearranja ou expõe todos os potenciais para o deslocamento da relevância, acumulados até aquela fase. O produto é então repentinamente visto sob uma óptica "ligeiramente diferente"' (KRUGMAN, 2002, p. 182).

A ação de compra desperta a "consciência" das qualidades do produto descritas pelo comercial. Não se pode dizer, portanto, que o comercial persuadiu o telespectador a comprar o produto, pois não houve, ao longo do processo, nenhuma "pré-disposição ou convicção mental" (Colley): "Tal mudança de atitude, após a compra do produto, não se encontra, como já foi dito, na 'racionalização' da compra; pelo contrário, é um aspecto da resposta emergente da percepção previamente modificada" (KRUGMAN, 2002, p. 182).

A partir dos resultados descritos acima, Krugman estabelece dois modos diferentes de influência dos meios de comunicação de massa: "Um deles é caracterizado pela falta de envolvimento pessoal que, embora seja mais comum nas repostas a material comercial, não está, de modo algum, limitado a ele. O segundo é caracterizado por um alto grau de envolvimento pessoal" (KRUGMAN, 2002, p. 184).

Somente o segundo modo de influência envolve o que normalmente chamamos de persuasão: "Quando o envolvimento é alto, o que se espera são os clássicos, mais dramáticos e mais familiares conflitos de ideias no nível de opinião consciente e atitudes que precedem mudanças visíveis no comportamento" (KRUGMAN, 2002, p. 184). Neste caso, a mudança de atitude ocasiona a mudança de comportamento; no caso do material de baixo envolvimento, como já vimos, o comportamento (situação de compra, por exemplo) produz a mudança de atitude.

Para Jones, o modelo de Krugman se aplica "a existência de novas marcas, de marcas em crescimento acelerado e aquelas em declínio acelerado", contudo, ele desconsidera "a situação mais comum das marcas estáticas", onde ocorre a constante interação, ou melhor, ressonância entre comportamento e atitude (JONES, 2002, p. 237-238). Segundo Jones, "nos termos de Krugman, esse processo pode abranger o uso da publicidade para aumentar o grau de envolvimento do consumidor com uma marca" (JONES, 2002, p. 237). 
Logo, para os consumidores frequentes, a publicidade torna-se gradualmente material de alto envolvimento, ocasionado assim a persuasão "clássica": o anúncio de um novo produto da Apple e sua notória fila de compradores bastam para exemplificar esse fenômeno. É por isso que Jones (2002) considera a teoria da compra repetida de Ehrenberg como uma extensão necessária à hierarquia do envolvimento insuficiente. Para essa teoria,

a sequência Consciência-Avaliação-Reforço parece dar conta dos fatos conhecidos. Segundo essa teoria, os consumidores primeiro adquirem consciência ou interesse no produto. Depois eles fazem uma compra de avaliação. Finalmente, um hábito de compra repetida pode ser desenvolvido e reforçado se houver satisfação após o uso prévio.

A publicidade tem um papel importante em todas as três etapas. Mas para produtos comprados frequentemente, a compra repetida é a principal determinante do volume de vendas, e aqui a publicidade deve mais reforçar do que persuadir (EHRENBERG, 1998, p. 63-63).

Acompanhando a famosa divisão proposta por Jones (1990), podemos definir tanto o modelo de Krugman quanto o de Ehrenberg como "teorias fracas", ao contrário das "teorias fortes" descendentes do modelo AIDA. Enquanto as primeiras compreendem a publicidade como reforço da compra, as segundas a entendem como causadora da compra. Colocando-se acima dessa dicotomia, há o modelo proposto por Richard Vaughn, também conhecido como "grade FCB" (da agência de publicidade Foote, Cone \& Belding). Ao invés de estabelecer uma hierarquia prévia, a grade FCB propõe múltiplas sequências, dependentes tanto do envolvimento do consumidor quanto da categoria do produto (VAKRATSAS; AMBLER, 1999, p. 28).

Revisando os modelos de publicidade anteriores, Vaughn apresenta três críticas: “(1) Os consumidores podem prosseguir através da sequência imperfeitamente (parar/começar, cometer enganos); (2) o feedback pode permitir que eventos anteriores influenciem atividades recentes; e finalmente, (3) os consumidores podem pular o processo inteiramente e se comportarem 'ilogicamente"” (VAUGHN, 1980, p. 29). Entretanto, sem ignorar as dimensões tradicionais da hierarquia dos efeitos, a grade FCB busca compreendê-las em múltiplas configurações, adotadas a partir de duas variáveis: uma decisão de compra racional ou emotiva; um envolvimento com o produto alto ou baixo. Combinando essas duas variáveis, Vaughn (1980) apresenta quatro possíveis hierarquias: 
PROGRAMA DE PÓS-GRADUAÇÃO EM COMUNICAÇÃO DA UNIVERSIDADE FEDERAL DE SANTA MARIA

\begin{tabular}{|c|c|c|c|}
\hline Variáveis & Hierarquia & Descrição & Produtos \\
\hline $\begin{array}{l}\text { Envolvimento } \\
\text { decisão racional }\end{array}$ & $\begin{array}{l}\text { alto, Cognição } \\
\text { Afeição } \\
\text { Conação }\end{array}$ & $\begin{array}{l}\text { "Isto implica uma grande necessidade de } \\
\text { informação por causa da importância dor } \\
\text { produto e de questões racionais ligadas a } \\
\text { ele" (VAUGHN, 1980, p. 30). }\end{array}$ & $\begin{array}{l}\text { Carros, } \\
\text { móveis, } \\
\text { produtos } \\
\text { novos, etc. }\end{array}$ \\
\hline $\begin{array}{l}\text { Envolvimento } \\
\text { decisão emotiva }\end{array}$ & $\begin{array}{l}\text { alto, Afeição } \\
\text { Cognição } \\
\text { Conação }\end{array}$ & $\begin{array}{l}\text { "Há envolvimento na decisão pelo } \\
\text { produto, mas informações específicas são } \\
\text { menos importantes que uma atitude our } \\
\text { emoção holística. Isto é assim porque a } \\
\text { importância está relacionada com a } \\
\text { autoestima da pessoa” (VAUGHN, 1980, } \\
\text { p. 31). }\end{array}$ & $\begin{array}{l}\text { Joias, } \\
\text { cosméticos, } \\
\text { moda, motos, } \\
\text { etc. }\end{array}$ \\
\hline $\begin{array}{l}\text { Envolvimento } \\
\text { decisão racional }\end{array}$ & 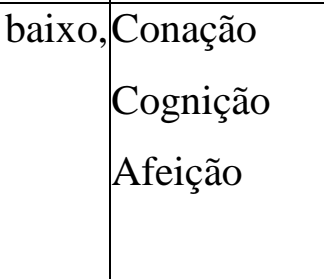 & $\begin{array}{l}\text { “A decisão pelo produto nesta área } \\
\text { envolve minimamente, e há a tendência de } \\
\text { formar hábitos de compra por } \\
\text { conveniência” (VAUGHN, 1980, p. 31). }\end{array}$ & $\begin{array}{l}\text { Comida, iten } \\
\text { domésticos, } \\
\text { etc. }\end{array}$ \\
\hline $\begin{array}{l}\text { Envolvimento } \\
\text { decisão emotiva }\end{array}$ & $\begin{array}{l}\text { baixo, Conação } \\
\text { Afeição } \\
\text { Cognição }\end{array}$ & $\begin{array}{l}\text { "Esta área de envolvimento baixo parece } \\
\text { reservada para aqueles produtos que } \\
\text { satisfazem gostos pessoais - cigarros, } \\
\text { bebidas, doces, filmes. Imagens e } \\
\text { satisfações rápidas são importantes" } \\
\text { (VAUGHN, 1980, p. 32). }\end{array}$ & $\begin{array}{l}\text { Cigarros, } \\
\text { bebidas, } \\
\text { doces, etc. }\end{array}$ \\
\hline
\end{tabular}

Quadro 1 - Os quadrantes da grade FCB

Fonte: Adaptado pelo autor de VAUGHN (1980)

A grade FCB mostra claramente que o modelo AIDA restringe-se aos produtos de alto envolvimento e decisão de compra racional. A compra somente ocorre após o convencimento, ou melhor, persuasão do consumidor. Por sua vez, a hierarquia afeição-cognição-conação também estabelece a compra como etapa final, mas ao invés de persuadir sobre as qualidades do produto, trata-se aqui de seduzir o consumidor em si. Podemos classificar ambas as hierarquias como "teorias fortes" (JONES, 1990).

Ao contrário dessas hierarquias, os modelos que estabelecem a compra como etapa inicial quase sempre abrangem produtos de baixo envolvimento, sujeitos ao processo de 
compra repetida. Percebe-se aqui os modelos de Krugman e Ehrenberg em funcionamento, pois a experiência satisfatória com o produto torna consciente as qualidades endossadas pela publicidade. A publicidade reforça então a compra repetida, apelando ou para hábitos de compra (decisão racional) ou para gostos pessoais (decisão emotiva). Temos aqui exemplos de "teorias fracas" (JONES, 1990).

Para Vaughn (1980, p. 32), o problema do modelo AIDA é que o consideraram por muitos anos como o único modelo legítimo, forçando sua linearidade em situações que não se aplicam; portanto, devemos entender as dimensões cognitiva, afetiva e conativa a partir de um conceito circular, ou seja, um conceito onde os pontos de partida e de chegada dependem do contexto (envolvimento, decisão de compra, categoria do produto, etc.). Percebemos assim que, do modelo AIDA à grade FCB, existem múltiplas configurações dos efeitos da publicidade, mas uma pergunta persiste: trata-se mesmo de efeitos em sequência?

\section{CRÍTICAS À HIERARQUIA DOS EFEITOS}

Após analisarem mais de 250 artigos e livros sobre os efeitos da publicidade, Vakratsas e Ambler (1999, p. 38) concluem que, apesar da importância das três dimensões (cognição, afeição e conação), o conceito de hierarquia (sequência temporal) não pode ser comprovado empiricamente; em seu lugar, os autores propõem um conceito espacial que envolve a avaliação simultânea das três dimensões. Do mesmo modo, para Weilbacher (2001, p. 2), devemos compreender as hierarquias apenas como uma explicação intuitiva e nãoválida do funcionamento da publicidade.

Vakratsas e Ambler (1999, p. 37) também concluem sobre a necessidade de mais pesquisas sobre metodologias de mensuração da afeição. Demonstrando claramente o estado da arte nessa área, Ambler afirma que, "quando você percebe pesquisas de marketing e publicidade mostrando que a persuasão lógica (cognição) é importante, provavelmente a razão é que elas não mensuraram nada mais" (AMBLER apud HEATH; FELDWICK, 2008, p. 40). Na verdade, o modelo AIDA (cognição-afeição-conação) e outras hierarquias equivalentes “não deixaram dúvida que 'o reino da cognição' é a chave para uma publicidade bemsucedida, e a emoção era uma consequência da cognição cuja influência era estritamente limitada por áreas de decisão envolvendo gosto e preferência" (HEATH; FELDWICK, 2008, p. 38; grifo dos autores).

Igualmente, Barry afirma que "os pesquisadores focaram demasiadamente no homem 
como um computador que recebe e processa informações, depois avalia essas informações e então se comporta baseado naquilo que processou” (BARRY, 1987, p. 275). Como já vimos, Heath e Feldwick chamam isso de modelo de processamento informacional (modelo IP); para eles, a adoção desse modelo mostra uma resistência de gestores e pesquisadores em tomarem decisões não baseadas em critérios verbalizados e racionalizados, portanto, em critérios essencialmente emotivos (HEATH; FELDWICK, 2008, p. 47). Ao disporem de dados verbalizados provindos de questionários (por exemplo, testes de recall), os gestores e pesquisadores buscam assegurar uma decisão racional, sem muitas vezes questionar se a metodologia é adequada ao anúncio avaliado. O processo criativo também é prejudicado, como mostram Heath e Feldwick:

O modelo IP persiste precisamente porque ele mantém a criatividade firmemente em seu lugar, como a serva de um processo que pode ser apresentado fundamentalmente como sujeito à análise e controle racional. A "criatividade" tende a assumir o mesmo papel na visão corporativa que o mundo espiritual no dualismo cartesiano: ela é permitida a existir e ser abordada como se fosse importante, mas porque não há como mensurá-la e torná-la passível de análise e controle, ela inexiste para todos os propósitos 'científicos' (HEATH; FELDWICK, 2008, p. 47-48).

Deve-se questionar inclusive a possibilidade efetiva de mensurar a criatividade e as emoções, contrariando assim aqueles que pedem por mais pesquisas quantitativas nessa área. Em suas críticas à hierarquia dos efeitos, Weilbacher apresenta um consenso pouco discutido, mas que muitas vezes pesa a favor dos modelos cognitivos: "Se os efeitos postulados da hierarquia são mensuráveis, então eles devem ser verdadeiros" (WEILBACHER, 2001, p. 4).

Ou seja, basta que um efeito seja mensurável para que ele seja aceito como verdadeiro. Ou melhor, para que um efeito seja verdadeiro, ela precisa ser mensurável. Percebe-se aqui mecanismos disciplinares em funcionamento: como afirma Foucault, "uma proposição deve preencher exigências complexas e pesadas para poder pertencer ao conjunto de uma disciplina; antes de poder ser declarada verdadeira ou falsa, deve encontrar-se, como diria $\mathrm{M}$. Canguilhem, "no verdadeiro"” (FOUCAULT, 1996, p. 33-34). Os aspectos criativos e emotivos jamais se encontram "no verdadeiro", pois eles dificilmente atendem a exigência da mensurabilidade. Em todo caso, isto pouco importa, pois "se o modelo está errado, as mensurações são irrelevantes" (WEILBACHER, 2001, p. 4).

De opinião semelhante, Barry e Howard (1999, p. 104) relatam a dificuldade em utilizar mensurações que incorporem completamente as três dimensões (cognição, afeição e 
conação); para os autores, o problema é ainda mais grave quando se percebe que não existem definições precisas dessas dimensões. Por exemplo, a afeição diz respeito somente aos sentimentos e emoções? A conação envolve apenas o comportamento de compra ou outros comportamentos relacionados ao produto (um fã divulgando sua marca favorita, uma dona de casa recomendando um produto recém-descoberto, etc.)? Na verdade, levando adiante esses questionamentos, percebe-se como "os sistemas cognitivo e afetivo na espécie humana é fortemente entrelaçado" (BARRY; HOWARD, 1999, p. 106). Como afirma Peterson et al.,

\begin{abstract}
A questão "a pessoa pensou ou sentiu primeiro" não é muito esclarecedora. Os indivíduos estão sempre em um fluxo de pensamento e sentimento; sendo assim, é irrelevante dizer que "existem alguns pensamentos precedendo um afeto" ou "existe afeição precedendo cognição". Ambas as atividade estão ocorrendo continuamente...As atividades mentais são dinâmicas, não estáticas. O ponto importante para ser respondido é como afeição e cognição interagem para influenciar o comportamento (PETERSON et al. apud BARRY; HOWARD, 1999, p. 108).
\end{abstract}

No momento em que se considera o entrelaçamento entre cognição e afeição, a validade da hierarquia dos efeitos é questionada, pois a visão de efeitos mais relevantes precedendo efeitos menos relevantes não se sustenta.

É importante notar, como mostram Barry e Howard (1999, p. 98), a diversidade de comunidades interessadas em discutir a hierarquia dos efeitos: pesquisadores e profissionais de publicidade e marketing, sociólogos, teóricos da comunicação, psicólogos cognitivistas, psicólogos sociais, etc. Vale a pena acrescentar a esse debate algumas comunidades praticamente ignoradas, mas que muito podem contribuir: os filósofos e os semioticistas. Sobre os filósofos, por exemplo, há considerações valiosas que podemos encontrar na fenomenologia da percepção, principalmente em sua crítica aos pré-juízos clássicos da psicologia, portanto, de uma ciência pioneira e predominante nos estudos da hierarquia dos efeitos publicitários.

Como vimos, a atenção é quase sempre citada como a primeira etapa das hierarquias tradicionais. Entretanto, para Merleau-Ponty, a atenção "é apenas uma hipótese auxiliar que se forja para salvar o prejuízo do mundo objetivo" (MERLEAU-PONTY, 2011, p. 27). Ou seja, a hipótese da atenção estabelece o mundo como único fenômeno positivo: se algo não é visto, então é porque houve falta de atenção. Deste modo, o conceito de atenção resguarda a objetividade do mundo normatizando a subjetividade do observador. Entretanto, para a fenomenologia da percepção, não se trata de atacar a objetividade do mundo, criando assim 
um relativismo sufocante para a verdade. Para Merleau-Ponty, "precisamos reconhecer o indeterminado como fenômeno positivo” (MERLEAU-PONTY, 2011, p. 27). Portanto, a desatenção, ou melhor, a distração, também constitui o mundo. Os publicitários devem considerar isso, ao invés de acreditarem que um consumidor distraído compromete a eficácia do anúncio.

Ao colocar a experiência no centro de sua filosofia, a fenomenologia da percepção também oferece uma solução para o suposto problema da precedência, pois, para ela, a afeição e a cognição somente existem a partir do corpo. Sobre a cognição, podemos dizer que “o sujeito da sensação não é nem um pensador que nota uma qualidade, nem um meio inerte que seria afetado ou modificado por ela; é uma potência que co-nasce em um certo meio de existência ou se sincroniza com ele" (MERLEAU-PONTY, 2011, p. 285). Portanto, não se trata de um sujeito que pensa sobre aquilo que está vendo, ou seja, um sujeito que presta atenção, se interessa, etc., mas de um sujeito que surge na medida em que seu corpo se harmoniza com o mundo observado. Segundo Merleau-Ponty, "uma excitação não é percebida quando atinge um órgão sensorial que não está 'harmonizado' com ela. A função do organismo na recepção dos estímulos é, por assim dizer, a de 'conceber' uma certa forma de excitação" (MERLEAU-PONTY, 2011, p. 114).

O corpo não é alvo da excitação, mas a concebe, fazendo-a surgir para ele: "se eu quisesse traduzir exatamente a experiência perceptiva, deveria dizer que se percebe em mim e não que eu percebo" (MERLEAU-PONTY, 2011, p. 290; grifo do autor). Dizer "eu percebo" é considerar a cognição como ponto de partida quando, na verdade, a reflexão somente ocorre quando algo já se percebe em mim, ou melhor, em meu corpo. Do mesmo modo, a respeito da afeição, não posso dizer, ao contrário, que sou afetado por um estado de emoção.

Como mostra Merleau-Ponty, “a reflexão sobre minha própria raiva nada me mostra que seja separável ou que possa, por assim dizer, ser deslocado de meu corpo" (MERLEAUPONTY, 2004, p. 45). A emoção não afeta o corpo, mas é ele quem a assume na medida em que a sente. Sendo assim, não se trata de um estímulo transmitido de fora do corpo (por exemplo, através de um anúncio). Para Sartre, a emoção "não poderia vir de fora à realidadehumana. Ao contrário, é o homem que assume sua emoção e, por conseguinte, a emoção é uma forma organizada da existência humana" (SARTRE, 2007, p. 27; grifos do autor).

Enquanto que, do ponto de vista da fenomenologia, a ausência da percepção compromete a hierarquia dos efeitos, a semiótica questiona por sua vez a ausência da significação. Em Semiótica da publicidade (1972), Georges Péninou mostra como o modelo 
AIDA favorece "mensagens graficamente fortes onde a imobilização da visão é confiada de bom grado à uma ilustração central muito atraente, uma convocação mais ótica do que semântica, mais saborosa do que substancial” (PÉNINOU, 1976, p. 35). Ou seja, o modelo promove o divórcio entre a função de "atrair a atenção" e a de "comunicar a mensagem" (JOANNIS apud PÉNINOU, 1976, p. 36).

A semiótica também permite pensar uma classificação como a apresentada pela grade FCB, sem depender, contudo, do conceito controverso de hierarquia dos efeitos. Floch (1993) constatou quatro tipos de valorizações publicitárias a partir do cruzamento entre valores de base (os objetivos do consumidor) e valores de uso (as utilidades do produto). Sendo assim, o primeiro quadrante da grade FCB (envolvimento alto, decisão racional) diz respeito ao que Floch chama de "valorização prática, que corresponde aos valores de uso concebidos como contrários aos valores de base (também pode-se dizer valores 'utilitários', que são a maneabilidade, o conforto, a robustez...)" (FLOCH, 1993, p. 147-148; grifo do autor); o segundo quadrante (envolvimento alto, decisão emotiva) diz respeito à "valorização utópica, que corresponde aos valores de base concebidos, mais uma vez, como contrários aos valores de uso (também se poderia dizer valores 'existenciais', que são a identidade, a vida, a aventura...)" (FLOCH, 1993, p. 148; grifo do autor); o terceiro quadrante (envolvimento baixo, decisão emotiva) diz respeito à "valorização crítica, que corresponde à negação dos valores 'existenciais' que podem ser atribuídos ao produto (a valorização crítica e a existencial são contraditórias, as relações qualidade/preço ou inovação/custo são valores críticos)" (FLOCH, 1993, p. 148; grifo do autor); e o último quadrante (envolvimento baixo, decisão emocional) diz respeito à “valorização lúdica, que corresponde à negação dos valores 'utilitários' (a valorização lúdica e a valorização prática são, portanto, contraditórias entre elas; os valores lúdicos são o luxo, a gratuidade, o refinamento, a 'pequena loucura'...)" (FLOCH, 1993, p. 148; grifo do autor).

Mais abrangente que a grade FCB, a proposta de Floch (1993) não se limita a pensar cada classificação ligada à uma categoria de produto, mas ela mostra como um mesmo produto pode desenvolver diversas valorizações dependendo do percurso narrativo desencadeado pela campanha publicitária. Portanto, a partir do significado, pode-se estabelecer tipos de envolvimento e tipos de decisão de compra. 


\section{CONCLUSÃO}

Mesmo diante das críticas apresentadas no tópico anterior, a pergunta inicial continua sem resposta: por que os publicitários ainda adotam e ensinam o modelo AINDA? $\mathrm{Na}$ verdade, para Barry e Howard, a tradição do modelo AIDA e da própria noção de hierarquia dos efeitos se justifica mais como soluções estratégicas e menos como dados empíricos: "a hierarquia dos efeitos se mostrou valiosa para ajudar a organizar o planejamento, treinamento e tarefas conceituais dentro de uma empresa" (BARRY; HOWARD, 1999, p. 108). Entretanto, ainda segundo os autores, "o fato de que existe uma diferença entre o uso do modelo como uma ferramenta heurística e suas realizações empíricas pode não ser uma questão crítica na mente de muitos profissionais" (BARRY; HOWARD, 1999, p. 108). Portanto, não se deve adotar o modelo esperando resultados previsíveis, principalmente porque "só houve tentativas limitadas de validar empiricamente a teoria, com resultados pouco conclusivos" (JONES, 2002, p. 236). Não se pode "assegurar que as leis publicitárias são da mesma natureza que as do mundo da mecânica" (SANT'ANNA, 2001, p. 79), ou seja, que os efeitos da publicidade seguirão uma mesma ordem pré-definida, como faz Sant'anna referindo-se ao modelo AIDA em seu manual de publicidade.

Contrariando Barry e Howard (1999), mesmo como ferramenta heurística e estratégica, a hierarquia dos efeitos dificulta o trabalho dos publicitários, principalmente dos criativos, pois muitas vezes as hierarquias priorizam a dimensão cognitiva, exigindo que os criativos justifiquem suas escolhas a partir de critérios racionais e mensuráveis. Tais critérios se colocam como os únicos disponíveis para um sistema organizacional preocupado com metas quantitativas e para uma visão de mundo dominada pela razão:

Em resumo, nós acreditamos que o modelo IP manteve sua predominância não porque ele funciona, mas porque ele faz o processo publicitário parecer verbal, racional, mensurável e passível de controle consciente. Ele se adapta tanto aos valores de nosso sistema organizacional quanto à ficção de um consumidor racional, como parte de uma visão de mundo iluminista. Qualquer outro modelo é considerado dissonante em relação a esses valores profundamente arraigados, sendo assim rejeitado ou como 'leve' e ineficaz ou como poderoso de uma forma sinistra (HEATH; FELDWICK, 2008, p. 49).

Essas considerações mais que respondem porque o modelo de processamento informacional e o modelo AIDA estão perdurando por tanto tempo. Não se trata de esquemas conceituais que supostamente facilitam o trabalho nas agências, mas de ideias que endossam 
valores e pontos de vista predominantes.

Ao invés desses modelos, os criativos estão em melhor caminho quando adotam as descobertas da fenomenologia da percepção, por exemplo. Um criativo deveria escolher e justificar a escolha de uma cor não porque ela atrai mais atenção, mas porque a cor anuncia-se "pela experiência de uma certa atitude do corpo que só convém a ela" (MERLEAU-PONTY, 2011, p. 284); apesar de intencional, o corpo desconhece as razões da psicodinâmica das cores. $^{3}$

O modelo AIDA e outras hierarquias equivalentes dificilmente conseguirão responder às dúvidas da publicidade, como, por exemplo, ao eterno enigma do desejo. Muitos podem acreditar que é impossível desejar o que não se conhece, confirmando assim a sequência canônica do modelo AIDA. Contudo, caso se queira saber se é possível desejar o que que não se conhece, não pergunte à um modelo científico. Pergunte ao corpo, ele sabe a resposta.

\section{REFERÊNCIAS}

ALDRIGHI, Vera. Eficiência publicitária e pesquisa de comunicação. In: RIBEIRO, Júlio et al. Tudo que você queria saber sobre propaganda e ninguém teve paciência para explicar. São Paulo: Atlas, 1995.

BARRY, Thomas E. The development of the hierarchy of effects: an historical perspective. Current Issues and Research in Advertising, v. 10, n. 2, p. 251-295, 1987.

BARRY, Thomas E.; HOWARD, Daniel J. A review and critique of the hierarchy of effects in advertising. In: ARNOTT, David; FITZGERALD, Maureen (eds.). Marketing Communications Classics: an international collection of classic and contemporary papers. Boston: Cengage Learning, 1999.

COLLEY, Russell H. DAGMAR: sistema de definição de objetivos publicitários para medir a eficiência da propaganda. São Paulo, Pioneira, 1976.

EHRENBERG, Andrew S. C. Repetitive advertising and the consumer. In: JONES, John Philip (ed.). How advertising works: the role of research. London: Sage, 1998.

FLOCH, Jean-Marie. Semiótica, marketing y comunicación: bajo los signos, las estrategias. Buenos Aires: Paidós, 1993.

FOUCAULT, Michel. A ordem do discurso. São Paulo: Loyola, 1996.

\footnotetext{
${ }^{3}$ Mesmo a semiótica deve resgatar sua raiz fenomenológica caso queira reaprender o sentido das cores: "não é preciso perguntar-se como e por que o vermelho significa o esforço ou a violência, o verde o repouso e a paz, é preciso reaprender a viver essas cores como nosso corpo as vive, quer dizer, como concreções de paz ou de violência" (MERLEAU-PONTY, 2011, p. 285). Não existe um código cromático, mas um corpo que vive as cores.
} 
HEATH, Robert; FELDWICK, Paul. Fifty years using the wrong model of advertising. International Journal of Market Research, v. 50, n. 1, p. 29-59, 2008.

HESS, Herbert. Advertising: questions and problems. New York: Universal Business Institute, 1910.

HOLLINGWORTH, Harry. Advertising and selling: principles of appeal and response. New York: D. Appleton and Company, 1913.

JONES, John Philip. Advertising: strong force or weak force? A dilemma for high education. Syracuse Scholar, v. 10, n. 1, p. 45-56, 1990.

. Hierarquias dos efeitos - Teorias da publicidade. In: JONES, John Philip (org.). A publicidade como negócio. São Paulo: Nobel, 2002.

KRUGMAN, Herbert E. Publicidade na televisão - Aprendizagem sem envolvimento. In: JONES, John Philip (org.). A publicidade como negócio. São Paulo: Nobel, 2002.

LAVIDGE, Robert J.; STEINER, Gary A. A model for predictive measurements of advertising effectiveness. Journal of Marketing, v. 25, p. 59-62, out. 1961.

LEWIS, E. St. Elmo. Financial Advertising: for commercial and savings banks, trust, title insurance, and safe deposit companies, investment houses. Indianapolis: Levey Bros. \& Company, 1908.

MALANGA, Eugênio. Publicidade: uma introdução. São Paulo: Edima, 1987.

MERLEAU-PONTY, Maurice. Conversas - 1948. São Paulo: Martins Fontes, 2004.

Fenomenologia da percepção. São Paulo: Martins Fontes, 2011.

PACKARD, Vance. A nova técnica de convencer. São Paulo: Difusão Cultural, 1972.

PALDA, Kristian S. The hypothesis of a hierarchy of effects: a partial evaluation. Journal of Marketing Research, v. 3, n. 1, p. 13-24, fev. 1966.

PÉNINOU, Georges. Semiótica de la publicidad. Barcelona: Gustavo Gilli, 1976.

SAMPAIO, Rafael. Propaganda de A a Z: como usar a propaganda para construir marcas e empresas de sucesso. Rio de Janeiro: Campus, 1999.

SANT’ANNA, Armando. Propaganda: teoria, técnica e prática. São Paulo: Pioneira, 2001.

SARTRE, Jean-Paul. Esboço para uma teoria das emoções. Porto Alegre: L\&PM, 2007.

SCOTT, Walter Dill. The psychology of advertising: a simple exposition of the principles of psychology in their relations to successful advertising. Boston: Small, Maynard \& Company, 1913.

SHELDON, Arthur Frederick. The art of selling. Libertyville: Sheldon University Press, 1911.

STARCH, Daniel. Advertising: its principles, practice, and technique. Chicago: Scott, Foresman and Company, 1914.

TIPPER, Harry; HOTCHKISS, George. Advertising: a practical presentation of the principles underlying the planning of successful advertising campaigns and the preparation of advertising copy. 
New York: Alexander Hamilton Institute, 1914.

VAKRATSAS, Demetrios; AMBLER, Tim. How advertising works: what do we really know? Journal of Marketing, v. 63, p. 26-43, jan. 1999.

VAUGHN, Richard. How advertising works: a planning model. Journal of Advertising Research, v. 20, n. 5, p. 27-33, 1980.

WEILBACHER, William M. Point of view: does advertising cause a "hierarchy of effects"? Journal of Advertising Research, v. 41, n. 6, p. 1-7, nov./dez. 2001.

WIJAYA, Bambang Sukma. The development of hierarchy of effects model in advertising. International Research Journal of Business Studies, v. 5, n. 1, p. 73-85, 2012.

Original recebido em: 30 de janeiro de 2016

Aceito para publicação em: 24 de janeiro de 2017

Rodolfo Rorato Londero

Doutor em Estudos Literários pela Universidade Federal de Santa Maria. Professor do Departamento de Comunicação e do Programa de Pós-Graduação em Comunicação da Universidade Estadual de Londrina.

Esta obra está licenciada sob uma Licença Creative Commons. 